\title{
Минерально-вещественный состав разломов Хибинского массива на примере данных по месторождениям Олений ручей и Расвумчорр: аспекты әволюции и варианты интерпретации
}

\author{
Маркович Д.И., Жиров Д.В. \\ Геологический институт КНЦ РАН, Anатиты,Dima153555@yandex.ru; zhirov@geoksc.apatity.ru
}

Аннотация. Работа приводит результаты исследований минерального и вещественного составов внутренней части разломных зон Хибинского массива на примере данных по месторождениям Олений Ручей и Расвумчорр. Делаются выводы о полихронности разломо- и сопутствующего минералообразования: начало формирования разломных структур Хибинского массива увязывается нами с позднемагматической - ранней постмагматической стадией, тектоническая активизация произошла примерно на палеоген - неогеновом этапе и продолжается в современное время в результате изостазии и активного освоения недр.

Ключевые слова: Хибинский массив, разлом, разломная зона, тектоника, гидротермальный, экзогенный.

\section{Mineral and chemical composition of the Khibiny massif faults on the example of data on the Oleniy Ruchey and Rasvumchorr deposits: aspects of evolution and interpretation options}

\author{
Markovich D.I., Zhirov D.V. \\ Geological institute KSC RAS, Apatity,Dima153555@yandex.ru; zhirov@geoksc.apatity.ru
}

\begin{abstract}
This article is devoted to the study of the mineral and chemical composition of the inner part of the fault zones of the Khibiny massif. The deposits of Oleniy Ruchey and Rasvumchorr were chosen as the object of research.This paper concludes about polychronicity the development of the fault zones and associated with mineral formation. The authors link the formation of fault structures of the Khibiny massif, with the late magmatic and early post-magmatic stages. Tectonic activation of fault zones occurred approximately at the Paleogene-Neogene stage and continues at the present time as a result of isostatic uplift of the Khibiny massif and active development of deposits.

Key words: Khibiny massif, fault, fault zone, tectonics, hydrothermal, exogenous.
\end{abstract}

\section{Введение}

Проблема разломной тектоники и сопутствующего минералообразования в Хибинском массиве имеет как фундаментальное, так и прикладное значение. В научном плане актуальность связана с вопросами постмагматической эволюции: с этапами и стадиями разрывной тектоники, гидротермального и гипергенного минералообразования в разломных зонах Хибинского массива. Прикладное значение обусловлено тем, что современное состояние и взаимоотношения в ряду «напряженно-деформированное состояние (НДС) - разрывные структуры - минеральные и вещественные изменения исходных пород» во многом определяют безопасность горных работ как в карьерах, так и на подземных рудниках. Если в отношении НДС и разломов существует множество хорошо апробированных измерительных и аналитических методов исследований и накоплены достоверные базы данных и знаний по каждому из эксплуатирующихся рудников, то изучение минерального и вещественного составов разломных зон, сопутствующих процессов минералообразования и изменения / выветривания выполнено с меньшей степенью детальности. Большинство результатов и публикаций по этой тематике приходятся на период до начала - середины 1980-х гг. (Дорфман, 1962; Онохин, 1975; Афанасьев, 1980; Дудкин, 2002 и др.). Практически все исследователи относят формирование разломов (так называемых зон шпреуштейнизации) и проявление сопутствующих процессов минералообразования к неотектоническому этапу развития массива. В то же время результаты выполненных исследований существенно раздвигают временные границы формирования и преобразования разломных зон, а также дополняют перечень сопутствующих процессов. 

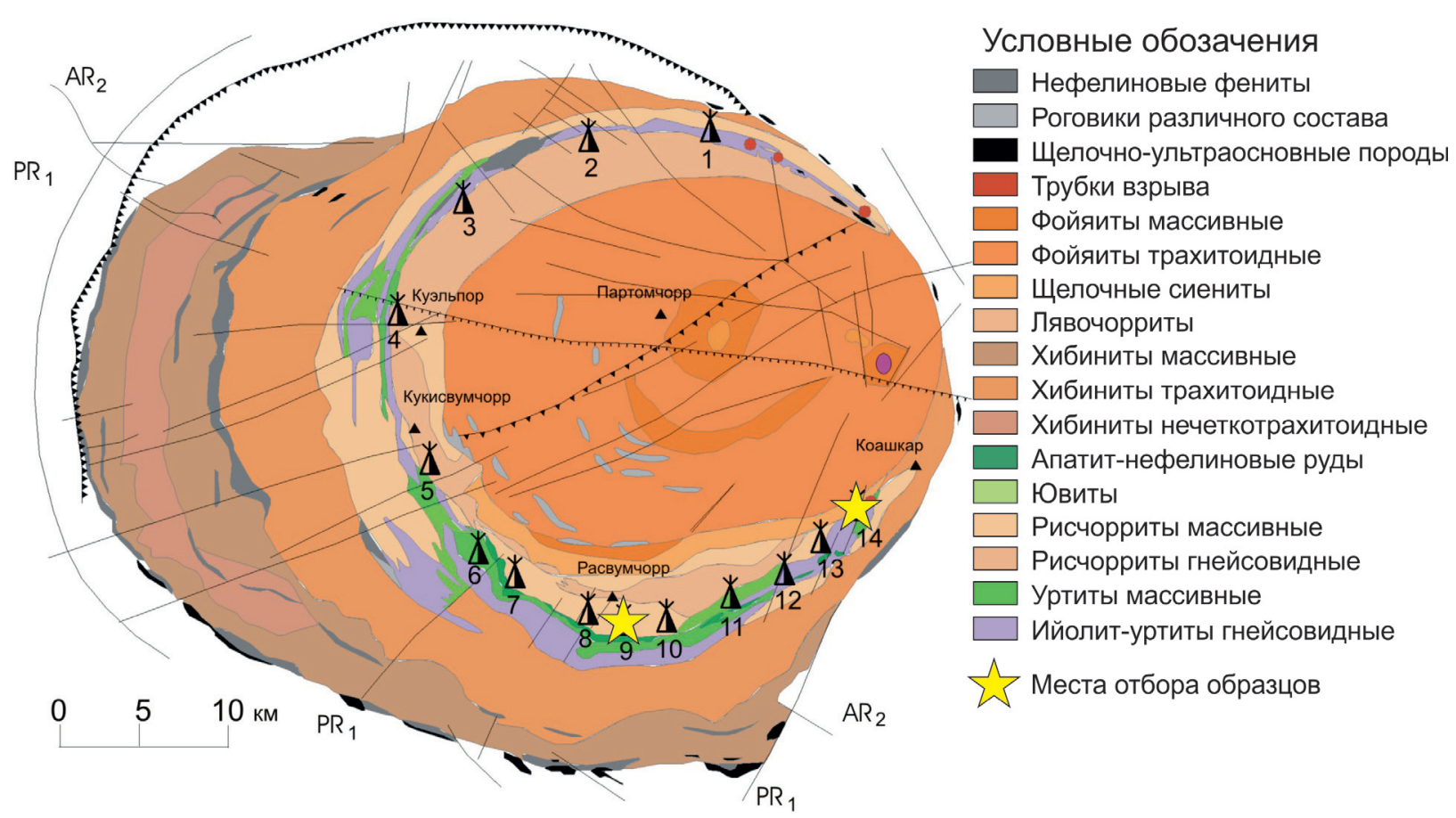

Рис. 1. Объекты исследования на геологической карте Хибинского массива: № 9 - Плато Расвумчорр, № 14 - Олений Ручей, по (Мультимедийный ..., 2001).

Fig. 1. The research objects on the geological map of the Khibiny pluton: № 9 - Plato Rasvumchorr, № 14 - Oleniy Ruchey, after (Multimedia ..., 2001).

Объектами исследований послужили массивы пород лежачего крыла месторождения Плато Расвумчорр (восточная часть южного борта карьера рудника «Центральный»), а также лежачего и висячего крыльев месторождения / карьера Олений Ручей (рис. 1).

\section{Исследование минерального и вещественного составов разломных зон}

Разрывная тектоника и трещиноватость месторождений Плато Расвумчорр и Олений Ручей многократно изучена на макро- и мезомасштабном уровне (Онохин, 1975; Титов, 1986; Zhirov et al, 2016 и др.). Однако вопросы эволюции разрывной тектоники во взаимосвязи с сопутствующими процессами изменения минерально-химического состава пород и руд исследованы не достаточно.

В ходе полевых исследований 2010-2020 гг. были отобраны образцы из ориентированного керна инженерно-геологической скважин (м-е Плато Расвумчорр) на разном удалении и внутри разломных зон с интенсивным проявлением шпреуштейнизации (или «окисления» в производственной терминологии) (рис. 2 А). Кроме того, были взяты образцы пород из центральной части разломной зоны карьера Олений ручей (рис. 2 Б).

Макроскопически образцы представляют собой в различной степени дезинтегрированные и изменённые (тектонически и минералогически) вмещающие породы (преимущественно уртиты), а также гидротермальные и гипергенные образования (жильные и зональные).

Петрографическое изучение жил показало, что их краевые части заполнены натролитом как минимум двух генераций (натролит второй генерации несет в себе ксенолиты и продукты изменения предыдущих фаз, вследствие чего имеет охряно-желтый цвет). Тела выполнения (гидротермальные жилы) выполнены преимущественно мелкозернистыми до аморфного состояния образованиями (рис. 3). Как правило, даже при больших увеличениях (X20-X40) едва различимы отдельные зерна. Поэтому основными методами исследований минералогического и вещественного состава жил стали микрозондовый и рентгеноструктурный.

Результаты микрозондового анализа - 14 (по 7 на каждый шлиф) определений вещественного состава минералов были пересчитаны по кислородному методу (Булах, 1967), в результате чего 


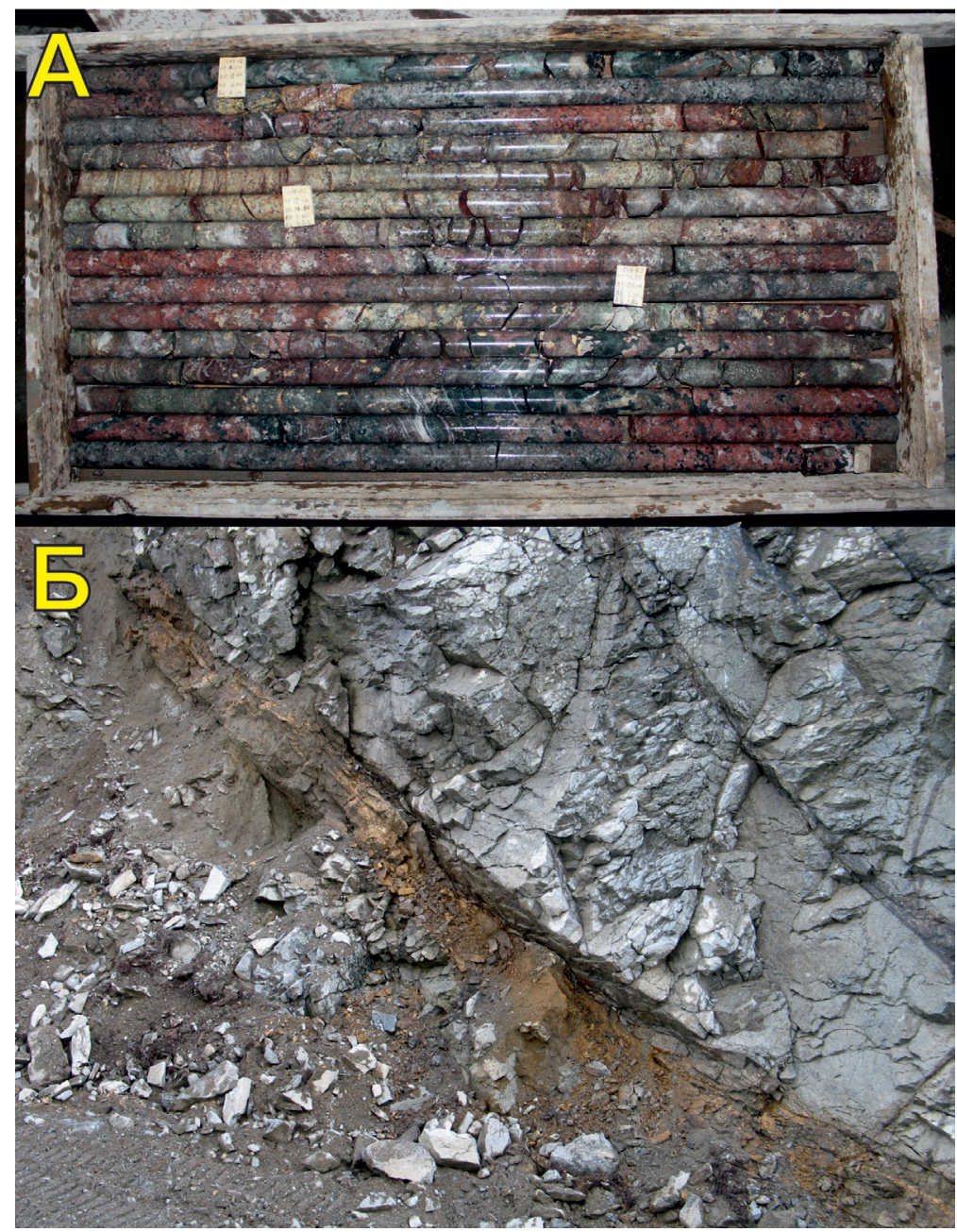

Рис. 2. А - керн инженерно-геологической скважины R-2 (Расвумчорр); Б - Выход Зоны Главного разлома в карьере месторождения Олений ручей.

Fig. 2. A - Drill core of the engineering-geological well R-2 (Rasvumchorr); B - Outcrop of the Main Fault Zone in the Western slope of the Oleniy Ruchey open pit.

был определен преобладающий минеральный состав тел выполнения (жил) и получены следующие расчетные формулы минералов:

$$
\begin{aligned}
& \text { Гидроксилапатит: } \\
& \mathrm{Ca}_{3.75-5.01} \mathrm{~K}_{0.00-0.32} \mathrm{Sr}_{0.00-0.14} \mathrm{Mg}_{0.00-0.03}\left[\mathrm{P}_{2.36-3.23} \mathrm{Si}_{0.00-0.39} \mathrm{Al}_{0.00-0.18} \mathrm{O}_{12.00}\right](\mathrm{OH})_{1.00} \\
& \text { Фторкафит: } \\
& \mathrm{Ca}_{4.03-4.80} \mathrm{Sr}_{0.05-0.53} \mathrm{Mg}_{0.01-0.06} \mathrm{Fe}^{2+}{ }_{0.00-0.02} \mathrm{~K}_{0.00-0.01}\left[\mathrm{P}_{2.55-2.81} \mathrm{Al}_{0.00-0.13} \mathrm{Si}_{0.00-0.06} \mathrm{O}_{12.00}\right] \mathrm{F}_{0.92-1.00}(\mathrm{OH})_{0.00-0.08} \\
& \mathrm{Na}_{0.00-0.01} \mathrm{~K}_{0.33-0.50} \mathrm{Mg}_{0.00-0.04} \mathrm{Fe}^{2+}{ }_{0.00-0.07} \mathrm{Al}_{0.49-0.95} \mathrm{Si}_{1.15-1.50} \mathrm{O}_{4.00} \\
& \text { Титанит: } \\
& \mathrm{Ca}_{0.96-0.99} \mathrm{Na}_{0.00-0.04} \mathrm{Fe}_{0.00-0.03} \mathrm{Ti}_{0.97-0.99} \mathrm{Si}_{1.00-1.01} \mathrm{Al}_{0.00-0.02} \mathrm{O}_{5.00}
\end{aligned}
$$

Титанит и кальсилит выполняют интерстиции между зернами апатита и натролита, а в центральной части жилы находится аморфный гидроксилапатит. Важно отметить, что кальсилит представляет собой, весьма вероятно, привнесенные ксенолиты и расположен главным образом в центральной части жил. Жилы обычно состоят из двух фаз: первая состоит из закономерных срастаний небольших по размеру кристаллов группы апатита (фторкафит) и титанита; вторая - представлена аморфным гидроксилапатитом, который выполняет обширные участки (рис. 4). 


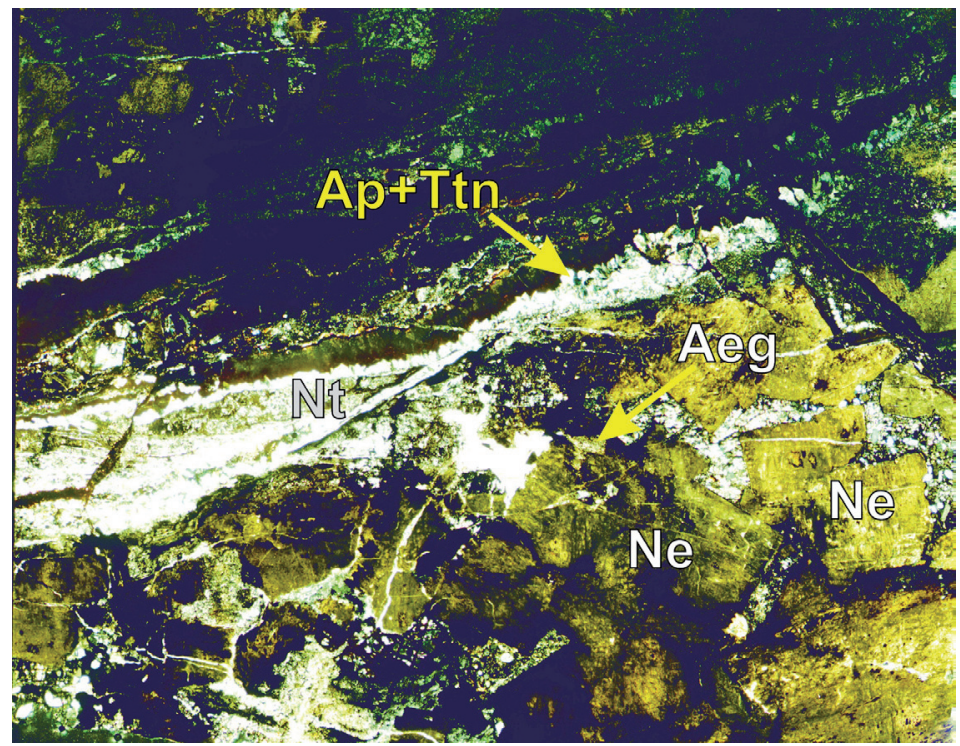

Рис. 3. Зональное строение натролитовой жилы (шлиф Rm 4-1). Краевые части жилы выполнены натролитом, далее к центру жилы выполнена закономерными срастаниями гидроксилапатита с титанитом, центральная часть жилы выполнена аморфным гидроксилапатитом. Обозначения: Аp - гидроксилапатит, Ttn - титанит, $\mathrm{Nt}$ - натролит, $\mathrm{Ne}$ - нефелин, Aeg - эгирин.

Fig. 3. Zonal structure of the natrolite vein (Rm 4-1 section). The marginal parts of the vein are completed of natrolite, further to the center (intermediate part of the vein) is filled in by regular accretions of hydroxylapatite with titanite; the central part of the vein is made of amorphous hydroxylapaite. Designations: Ap - hydroxylapatite, Ttn - titanite, $\mathrm{Nt}$ - natrolite, $\mathrm{Ne}$ - nepheline, Aeg - aegirine.

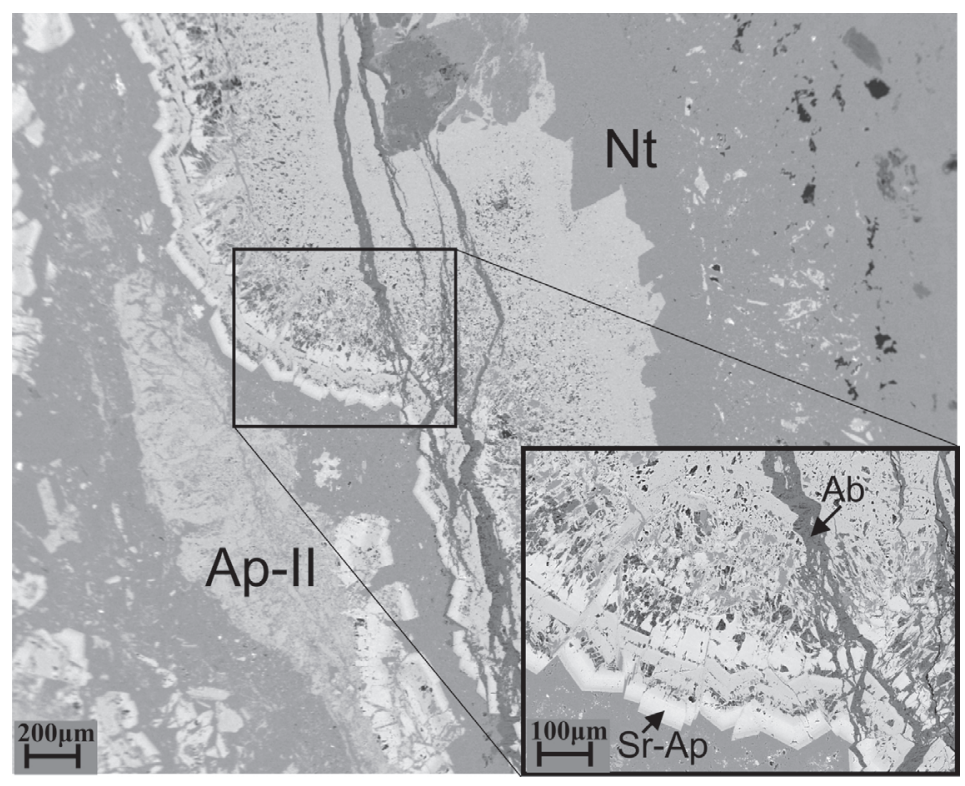

Рис. 4. BSE изображение строения центральной части натролитовой жилы. Обозначения: Sr-Ap - фторкафит, Ap-II - гидроксилапатит, $\mathrm{Nt}$ - натролит, $\mathrm{Ab}$ - альбит.

Fig. 4. BSE image of the central part structure of the natrolite vein. Designations: Sr-Ap - fluorcaphite, Ap-II - hydroxylapatite, $\mathrm{Nt}$ - natrolite, $\mathrm{Ab}$ - albite.

\section{Заключение}

Исследования минералогического и химического составов показали полихронность тел выполнения (жил, внутренних частей разломов, брекчий) и их гетерогенность. В жилах и цементе брекчий обнаружены минералы, не характерные для дресвяно-гидрослюдистых кор выветривания. 
Весьма вероятно, что начало формирования разломных зон связано не с неотектоникой (Афанасьев, 1980; Дудкин, 2002), а с завершающими стадиями становления Хибинского массива (позднеили/и ранняя постмагматическая стадии). Об этом свидетельствуют высокотемпературные и «глубинные» парагенезы тел выполнения (гидроксилапатит и титанит) и ксенолиты (кальсилит). В то же время в разломных зонах весьма широко развиты процессы «окисления» - выветривания (шпреуштейнизация, образование смектитов, гидрослюд и др. глинистых минералов и т.п.). Поэтому эволюция разломных зон, вероятно, подразумевает пространственное совмещение нескольких разновременных процессов, включая поздне- или/и раннюю постмагматическую тектонику и гидротермальную проработку, мезозойский этап корообразования и, наверно, современный гипергенез.

\section{Благодарности}

Авторы благодарят за всестороннюю поддержку и помощь в проведении исследований П.А. Корчака, А.А. Стрешнева и П.Л. Глазунова (АО Апатит), а также Меньшикова П.Ю. и Сергеева Ю.И. (АО СЗФК).

Исследования выполнены в рамках темы НИР № 0226-2019-0053.

\section{Литература}

1. Афанасьев А.П. История формирования кор выветривания и гипергенных полезных ископаемых на Кольском полуострове в мезо-кайнозое // Геология и полезные ископаемые мезо-кайнозойских образований Кольского полуострова. Апатиты. Изд-во: КФ АН СССР. 1980 б. С. 5-36.

2. Булах А.Г. Руководство и таблицы для расчета формул минералов. 2-е изд., испр. и доп. М. Изд-во: Недра. $1967.144 \mathrm{c}$.

3. Дорфман М.Д. Минералогия пегматитов и зон выветривания в ийолит-уртитах горы Юкспор Хибинского массива. М.-Л. Изд-во: АН СССР. 1962. С. 168.

4. Дудкин О.Б. Фанерозойские коры выветривания в щелочных массивах Кольского региона // Мурманский вестник. Т. 5. № 1. 2002. С. 3-8.

5. Костылёва-Лабунцова Е.Е., Боруцкий Б.Е., Соколова М.Н., Шлюкова 3.В., Дорфман М.Д., Дудкин О.Б., Козырева Л.В., Икорский С.В. Минералогия Хибинского массива. Т. 1. Ред. Чухрова Ф.В. М. Изд-во: Наука. 1978. 230 с.

6. Мультимедийный справочник по минерально-сырьевым ресурсам и горнопромышленному комплексу Мурманской области: Цифровой информационный ресурс. Ред. Ф.П. Митрофанова, А.В. Лебедева / Отв. руководитель Д.В. Жиров / Отв. исп.: В.Ю. Калачев, С.А. Климов, Н.О. Сорохтин / Соисп.: Комитет природных ресурсов по Мурманской области, С.В. Жабин, Н.И. Бичук, В.А. Чапин, В.Г. Зайцев / Сост.: Б.В. Афанасьев, Б.В. Гавриленко, В.И. Пожиленко и др. Апатиты. Изд-во: ГИ КНЦ РАН. 2001. Ч. 1: Геология и минерально-сырьевые ресурсы - 460 мб. Ч. 2: Горнопромышленный комплекс - 680 мб.

7. Онохин Ф.М. Особенности структуры Хибинского массива и апатитонефелиновых месторождений. Л. Изд-во: Наука. 1975. 106 с.

8. Титов В.Н. Структурные особенности апатитовых месторождений Хибинского массива // Труды ГИГХС. 1986. 87 с. (Рукопись депонир. В ОНИТЭХИМ г. Черкассы. № 1396-хп87).

9. Zhirov Dmitry, Klimov Sergey, Zhirova Anzhela, Panteleyev Alexey. 3D Modeling for Identification and Analysis of Geodynamic Hazards in the Rasvumchorr Mine - Central Open Pit Natural-Technical System (Khibiny) / Conference Proceedings The 16th International Multidisciplinary Scientific GeoConference \& EXPO (SGEM-2016), Albena (Bulgaria) 30 June -06 July 2016. Albena (Bulgaria), 2016. Book 1: Science and Technologies in Geology, Exploration And Mining. V. 3. :Hydrogeology, Engineering Geology and Geotechnics. P. 3-14. 